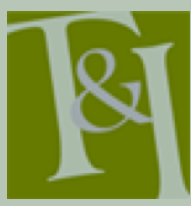

The International Journal for Translation \& Interpreting Research

trans-int.org

\title{
From translation briefs to quality standards: Functionalist theories in today's translation processes
}

\author{
Elisa Calvo \\ Universidad Pablo de Olavide (Spain), Interglosia Research Group (HUM 996)
}

ecalenc@upo.es

DOI:10.12807/ti.110201.2018.a02

\begin{abstract}
Functionalist theories of translation seem to have their roots in the examination of professional translation processes. The functionalist notion of skopos (Vermeer, 1996) focuses on the purpose of the translation project, highlighting a concept that potentially links TS with professional practice: the brief. While many translators receive sparse or insufficiently explicit briefs (Byrne, 2012), in other cases, translation vendors develop extremely complex specifications encompassing a wide range of different constraining elements at different levels. This paper analyses how, if at all, different models or systems of skopoi and briefs can be incorporated into today's professional market. Special emphasis is placed on the potential correlation between functionalist concepts and translation industry normalization instruments (such as ISO 17100).
\end{abstract}

Keywords: translation quality, standards, functionalist approaches, brief, specifications.

\section{Translation markets and contemporary translation theories}

This paper explores the possible connection between functionalist theories of translation and actual operating procedures within the translation industry. It also looks at possible relationships between the main concepts underlying these explanatory theories and real-life translation processes and standards. Translation Studies (TS) have always scrutinised and questioned the link between professional translation and translation theories. A key work in this field is the essay Can Theory Help Translators? (Chesterman \& Wagner, 2002), which offers an interesting and in-depth discussion of the extent to which professional translation experiences (Wagner) are reflected in research, and theory-based approaches to translation (Chesterman). Wagner's initial scepticism is rooted in her day-to-day work as a translation project manager for European institutions, which leads her to question whether translation theories are useful for translators at all. In contrast, Chesterman focuses on the need, applicability and practicality of some translation theories. Since 2002, when the book was published, the translation industry has experienced dramatic changes in many different areas: technology, norms and standards, productivity factors, financial and profit-related aspects and the appearance of a wide range of value-added translation-related services. This evolution 
rekindles the long-standing debate over translation theory versus translation practice, particularly in the light of functionalist theories.

In previous works, a number of translation scholars have sensed possible connections between functionalist theories and different aspects of the translation industry:

Works by functionalists such as Reiss (1980), Reiss and Vermeer (1984), and Nord (1997), particularly their notions of text types and of the skopos of translation are useful for understanding and describing whereby translation and localization project managers identify project objectives and determine project scope. (Dunne \& Dunne, 2011, p. 6)

One of the most important achievements of Skopos theory and functionalism in translation was to take the translating and interpreting profession seriously. (Nord, 2012a, p. 29)

Functionalist theories have had the greatest impact in the industry, partly perhaps because functionalist theories are probably inspired by observation of the translation market in operation. (Alonso \& Calvo, 2015, p. 143)

The translation industry itself seems to change radically every few years due to technological advances, the transformation or diversification of preexisting translation-related services (see value-added services as in EN 15038, ISO 17100) and its growing status as a sector of economic activity. Professional translation services have progressively branched out into different activities such as localization, certified translation, transcreation, post-editing, multilingual content management, etc. This paper examines whether functionalist theories originally inspired by the translation profession as it was back in the 1980s and 1990s are still relevant and potentially influential in today's highly specialized, technified industry.

Assignments, briefs or commissions, as defined by Vermeer (1978; 1996), Nord (1991) and Fraser (1996), are theoretical constructs of particular interest in this study insofar as they determine the functional notion of quality in translation, as discussed below. The functionalist ideas behind brief and quality revolve around the core role played by the commissioner, or client, in the translation equation, together with the impact of their expectations and their communicative needs on the translation process (Parra, 2005, p. 67). Furthermore, at a more abstract and philosophical level, the central concept of skopos (Vermeer, 1996), understood as the aim or purpose of a translation, represents the fundamental principle behind the main functionalist approaches. The frequently muddled concepts of brief and skopos can be linked with Aristotle's hylomorphism, which conceives a specific reality as a doublefaceted compound of essence (i.e., in our context, skopos: an intentional motive which can be construed but is not always tangible) and matter (i.e., the brief: an explicit piece of information which informs about skopos-related features).

Functionalist theories have also been shaped by other related constructs such as translational action (Holz-Mänttäri, 1984), adequacy (Vermeer, 1996), functionality and loyalty (Nord, 1991; 1997). According to these notions, which are conceptually related albeit with subtle differences in perspective, translators are seen as active, intentional agents who have the power to act on their translations, taking into account different professional and ethical standpoints, and who are able to work in accordance with a subjective notion of quality which reacts or adapts to each incoming translation commission: 
(...) we have to look for another yardstick to measure translation quality. Functionalist approaches to translation suggest that it might be helpful to ask whether or not the product of a translation process achieves the intended communicative function. (Nord, 1997, p. 42)

Functionalist principles are not always ideally apparent in real life. A number of authors have questioned the validity or realism of the axioms linked to central functionalist concepts. In their experience, translators very often do not receive sufficient clarification as to what their clients or audience really need, and explicit briefs are simply non-existent in many cases:

A professional gets a commission and a source text from a client who is generally a layperson and has no idea about the target or the source culture and language. The information the translator gets from him is very vague. Mostly the client just says that he needs a translation until day X. (Sunwoo, 2007, p.3)

Producing a translation brief is quite a hit and miss affair with clients rarely able to provide anything more relevant or specific than "I have a 7,500-word document that I need translated. It's got something to do with electronics and I need it by the end of the week". (Byrne, 2012, p. 13)

At the other end of the spectrum, one previous work (Alonso \& Calvo, 2015) described just the opposite reality: the highly specialized translation and localisation industry frequently generates more and more sophisticated and exhaustive instruction kits (Esselink, 2002) which continually grow in complexity and specificity in order to meet extremely precise translation product and process quality criteria. One of the main questions here, then, is whether the trend is towards a progressive desertion of what we understand by brief (explicit skopos), or whether, quite to the contrary, the industry is progressively adopting or assimilating certain functionalist notions. The latter possibility would imply the industry might be embracing extremely exhaustive systems of skopoi, which are used to instruct about a very precise projectbased notion of quality. A possible interdependence might be established between functionalist approaches and quality management systems in contemporary professional translation contexts, as translation norms and standards seem to mirror functionalist principles to a certain extent. As Arevalillo points out, for instance, the EN 15038 standard reflects how functionalist theories may have implications for translation project management because such theories focus on translation not only as a product but also as a process and a service that are equally subject to the standard (2015, p. 223).

In view of the above considerations, the main question addressed in this paper is therefore whether functionalist theories are actually gaining in importance vis-à-vis translation practice or rather becoming redundant.

\section{Functionalist approaches to translation}

As posed by Reiss and Vermeer (1978; 1996; 2004), Nord (1991; 2012b), Chesterman (2010) and others, the following theoretical hypotheses could help summarise the main functionalist assumptions:

- The purpose or function of a translation determines the methods and strategies to be applied (principle of functionality) (Nord, 1991)

- Translation, like any other human action, is necessarily intentional, and embeds a purpose (skopos), whether explicit or implicit (Reiss \& Vermeer, 1984, cfr. 2013; Vermeer, 2004) 
- Translations are not normally reversible and a given source text has many possible translations. (Reiss \& Vermeer, 1984; Chesterman, 2010). A translation is a representation of the source text, but it responds to a specific skopos. This has hermeneutical implications for the concepts of equivalence and quality (Nord, 1997, p. 42)

- Clients or commissioners can define a translation's expected function or purpose (brief, commission). However, the brief may not always be clear (Reiss \& Vermeer, 1984; Chesterman, 2010). Whenever the brief is not obvious, translators can deduce the purpose of the translation for themselves (implicit or tacit skopos)

- Quality is linked to functionality (Nord, 1991). Ideally, good, adequate translations will respond to the communicative function(s) expected by the target audience (Nord, 1991; Chesterman, 2010)

- A translation's skopos and function(s) may often differ from those of the source text (Nord, 1997; Chesterman, 2010), particularly when there is a lack of cultural equivalence between the source and the target contexts

The key idea, as stated above, is that translation as a human action is always intentional (Reiss \& Vermeer, 1984, p. 119; Vermeer, 1996; 2004; Holz-Mänttäri, 1984; Nord, 1997). As Chesterman (2010, p. 224) explains, "translators should consider the purpose of their translations - (this) certainly helped to shift the focus of theoretical thinking away from equivalence towards other relevant factors and agents which affect the translation process". It is the purpose inferred by translators which "determines translation methods and strategies, and not the function of the ST" (Nord, 1991, p. 16), i.e., purpose determines translation processes and quality.

\section{Skopos theory and the translation market}

As stated above, the Greek term skopos is a theoretical reference to the aim and purpose of a translation (Vermeer, 2004). The skopos theory has had a remarkable impact in TS, although it has also received major criticisms (Sunwoo, 2007; Martín de Leon, 2008; Chesterman, 2010; among others) with regard to its scientific adequacy, empirical validity, construct consistency, ethical implications, etc. Some of these criticisms were reviewed and examined by Vermeer (2004).

In some cases, some scepticism is evident in purely professional translating circles. This may be rooted in conceptual misinterpretations. For example, Byrne $(2006 ; 2012)$ seems to mix up or equate the concepts of brief and skopos (i.e., implicit skopos and explicit skopos or brief). According to Byrne, skopos could be defined as the customer specifications to be considered in a particular translation project (Byrne, 2006, p. 39). Byrne argues that skopos theory diverges from translation practice because translators rarely receive any detailed instructions containing the minimum information they require for the translation process. However, as explained earlier, the skopos can always be inferred or deduced in the absence of any clear, explicit indications (brief). Indeed, some studies (Fraser, 1996; Schjoldager \& Zethsen, 2003; Jensen, 2009) show that most translators actually work with a conjectural brief in mind (an inferred skopos) without being given one explicitly.

One factor that might affect whether translators receive briefs is the type of client (Nord, 1997; Jensen, 2009). Some clients seem unwilling or unable to provide briefs, because they do not understand or are unaware of the 
complexity of translation processes. Furthermore, for many translators working with translation agencies, particularly small and medium-sized agencies, clear briefs are not frequent, and project management processes are ripe for improvement (Alonso \& Calvo, 2015). In other cases, "translation agencies or vendors put a great deal of effort into preparing specifications and instructions for the translator" and "translators can be confronted with a variety of possible situations: from lacking skopos, that translators would need to construct or make explicit in order to produce purposeful translations, to extremely detailed, descriptive and subordinating instructions" (ibid., p. 43). For certain types of projects, extremely exhaustive skopoi or highly complex brief systems are becoming increasingly frequent, often including style guides, instructions to use computer assisted translation tools, technical configurations which will affect format and decision-making, general or specific descriptions of the audience, glossaries and other reference sources, or basic project data in the form of contract-like documents such as project orders or purchase orders (Risku, 2009, p. 274), etc.

Arevalillo points out that a project starts only when the terms for it have been agreed by both client and translator (2015, p. 67). Specific managerial processes produce their own document genres which involve explicit skoposrelated content and are legally binding for the agents involved. Among such managerial skopos-related documents, Arevalillo (ibid.) highlights the following:

- Quotations

- Framework contracts or outline agreements

- Project orders (which frequently specify languages, deadlines, number of words, format, etc.)

- Plain e-mail requests, including the basic commission-related data, which compensates for the absence of more formal contractual or financial documents

A number of additional instructional documents cover a range of different aspects and levels of specifications, encompassing linguistic, technological, terminological, functional and/or managerial considerations. These specifications, either deliberately or unintentionally, may impact translation processes, decision-making and quality. Low quality or extremely complex specifications might be counterproductive, whereas negligence in the use of this additional material could have a negative impact on the quality of the translation and on the translator's productivity (Sere, 2015, p. 107). For the sake of effectiveness, specifications should therefore be developed coherently and under a global managerial vision of the project, always taking into account the impositions and functional constraints that such indications represent for the translator's work. Efficient project management would benefit from a global, functionalist approach to translation project workflows and quality (Risku, 2009; Arevalillo, 2015):

Customer-focused quality management requires that clients specify their requirements; however, translation customers often cannot specify their requirements because they have little or no knowledge of the languages, cultures, conventions and legal requirements of the target locale. (...) These problems are magnified in localization projects, which present a greater degree of complexity than document translation projects. (Dunne \& Dunne, 2011, p. 160).

Technology-mediated translation workflows seem to generate more complex briefs and skopoi (Alonso, 2016). Although translators are always in 
a position to oversee technology-mediated translation processes, translation decision-making is more constrained when specific tools (e.g., memories and text segmentation) or mark-up languages (Pym 2011; De la Cova, 2012) are in place. The type of specifications frequently found in highly specialised branches of the industry such as localization and technical content translation services, dominated by project and quality management systems, for instance, can be described as 'multi-layered brief systems' due to their complexity. These multi-layered systems may in turn comprise explicit and implicit instructions and constraints. Explicit directions are usually called project specifications rather than briefs or commissions in applicable industry standards (ISO 17100). Implicit constraints underlying those given instructions may require further research, and experienced, and well-trained project managers should bear those unexpected subordinating effects in mind.

\section{Skopoi, briefs and skopoi-related systems}

After compiling a corpus of skopos-related materials received by 12 different translators located in Spain - eight of whom work on a freelance basis while four work in-house for different language service providers-, a qualitative analysis was carried out with the intention of gaining an insight into the different levels of explicitness which exist in translation project skopoi. To compile the corpus, the translators were asked to provide any kind of written information, orders, request messages, specifications or instructions explicitly received from their clients. Clients included national and international vendors, as well as private non-translation-related clients. A total of 38 projects were eventually documented in the corpus. The translators were also asked to conceal any sensitive pieces of information for purposes of client and project confidentiality, sensitive data being replaced with the tag [XXX].

This preliminary qualitative approach opened the door to further quantitative research aimed at ascertaining which type of skopoi tends to be more frequent for each translation-related service or industry branch, since the qualitative results suggested that the type of skopos might well be related to the specific service or market brand involved. The specific corpus compiled in this study suggested that three possible categories of skopoi can be characterised, with varying levels of explicitness, as described below.

\subsection{Skopos type 1: virtual absence of explicit specifications}

As in the cases noted by authors like Nord (1997), Byrne (2012), Sunwoo (2007) and Jensen (2009), the translators in our study received little or no specifications for their projects mostly when clients were laypersons or did not belong to the translation industry, probably because such clients do not fully understand the complexity of the translating process. In some cases, there was virtually no explicit brief because the clients expected the translators to infer the brief by themselves (e.g., the translator had previously worked for that client on that particular kind of project) or because the type of project tacitly required a specific approach, as in the case of sworn translations in Spain. This correlates to Nord's explanations of implicit skopos:

the first step in the translation process is the "interpretation of the brief", drawing on whatever information there is or can be obtained about the "profile" of the target text the client needs. In routine tasks from well-known clients, for example, the translator may rely on previous experience; in "standard briefs" (like translating a set of operating instructions for a similar audience to achieve the same communicative function as that of the source text), they may simply follow the culture-specific norms for this kind of translation. Any task that is 
not standard or routine, will have to be specified before the process is initiated. (2006, p.30)

The example below (edited to protect confidential data) illustrates this type of succinct brief. All the examples of this kind within the corpus took the form of a plain e-mail request (Arevalillo, 2015). A total of 13 cases out of 38 easily fitted this category.

Example 1: Almost no explicit specifications (emphasis on skopos-related elements)

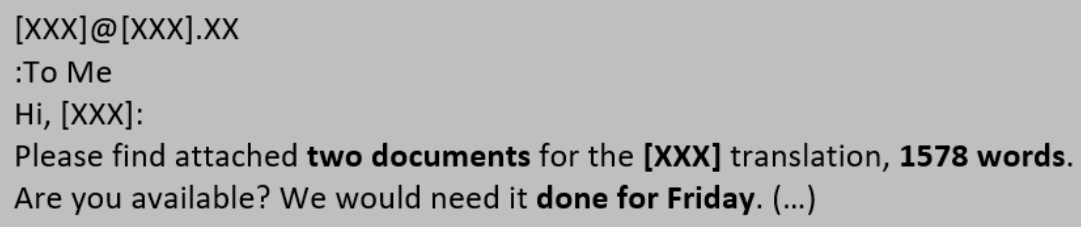

\subsection{Skopos type 2: explicit specifications covering basic functional data}

Vermeer (2004, p.235) maintained that a commission or brief should ideally comprise as much detailed information as possible, particularly on the following: (1) the goal, i.e., a specification of the aim of the commission; (2) the conditions under which the intended goal should be attained (naturally including practical matters such as deadline and fee).

The example below (edited to protect confidential data) contains basic skopos-related information including text genre, directionality, word counts, deadlines, and technological requirements (tools). In these cases, translators received the information that Vermeer considered essential, making it possible to adopt a coherent standpoint when inferring or determining a basic notion of skopos-led quality. Most commissioners of this type of job came from within the translation industry.

Example 2: Specification of basic functional elements (emphasis on skoposrelated elements). Text translated from Spanish

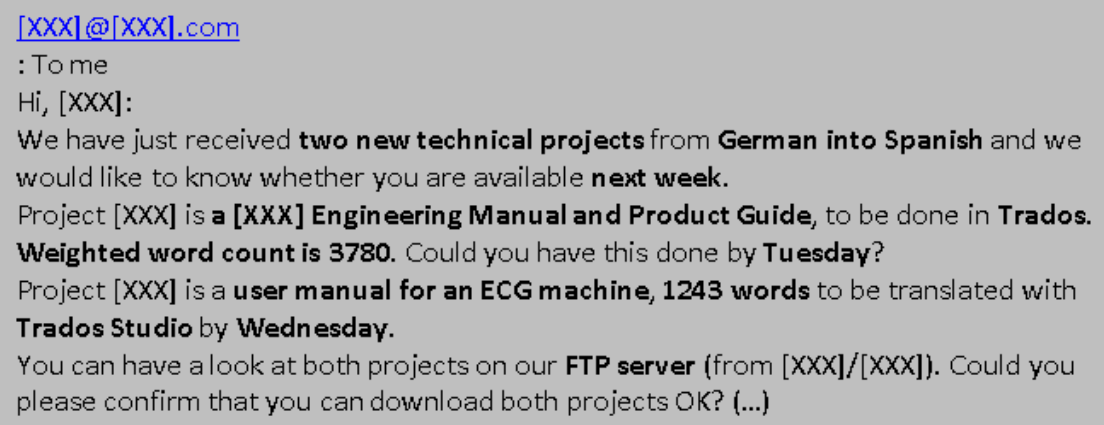

Examples 1 and 2 illustrate how many (mostly freelance) translators often have the opportunity to analyse the source text before accepting a project. From a functionalist point of view, this is an essential pre-translation analysis stage. No matter how explicit the brief is, without this preview, translators do not actually know what to expect and what specific constraints and difficulties 
the project may pose for their work. A total of 15 cases were assigned to this category.

\subsection{Skopos type 3: Complex brief (multi-layered brief system)}

From a project management localization perspective, Esselink described the notion of translation kit (also localization kit or lockit in localization contexts), a concept which refers to a package of files containing the information necessary to meet the client's quality criteria:

When all the translatable files have been identified and prepared for translation, a "translation kit" is sent out (to the translator), which contains all the resource files that need to be translated, all the tools required, plus instructions for the translators on how to deal with the various files and file types. Building these "translation kits" is an important task for localization engineers. (Esselink, 2002, p. 4)

More recently, authors like Roturier (2015) or De la Cova (2016) have also described the importance of these so-called translation kits or lockits as an established component of highly technified projects such as app localization projects.

Analysis of translation kits reveals multi-layered brief systems made up of a wide range of skopos-related content, including:

- Indications concerning the degree of adaptation to target

- Compliance with domain or client terminology and/or style

- Detailed style guides

- Software and other technical configurations

- Instructions to cloud or remote translate in collaboration with other professionals

- Translation memories, automatic translation and post-editing instructions

- Mark-up language

- Glossaries, sources \& references, parallel documentation

- Basic order information (words, rate, delivery date)

- Terminology databases

- Project management files or folders (kit) setting out instructions

- Question \& Answers (Q\&A) systems

- Application of technical standards and metrics (ISO, EN, DIN, etc.; MQM scorecard, LISA QA...)

Brief systems can thus be structured in various skopos-related levels or layers, in accordance with specific aspects of individual projects such as:

- Style and language choice: style guide, spelling, register, market conventions, etc.

- Functionality: type of service (adaptation, localization, transcreation, post-editing, revision, etc.); information on recipients, quality or assessment system, etc.

- Technology: impact of technologies (e.g., translation memories, automated translation with post-editing) and mark-up languages

- Terminology: glossaries, terminology management systems, parallel reference texts, use of translation memories with terminological functions, etc.

- Management: basic project data, project order, contract, etc.; deadline, word count, delivery system, management formats 
(folders, file names, fees, etc.); coordination of format and quality with project manager (Q\&A or other feedback modelling resources), etc.

These elements can be either explicit or implicit, and whenever they are explicit they can also have unintended and/or implicit consequences for the translation process. Skopoi-related information can be extracted from different materials, from plain e-mail requests to specific subordinating materials such as style guides. The following example illustrates the complexity of some specifications.

Example 3: Initial instructions for a complex technological project (multilayered brief system with different skopos-related implications) (emphasis on skopos-related elements)

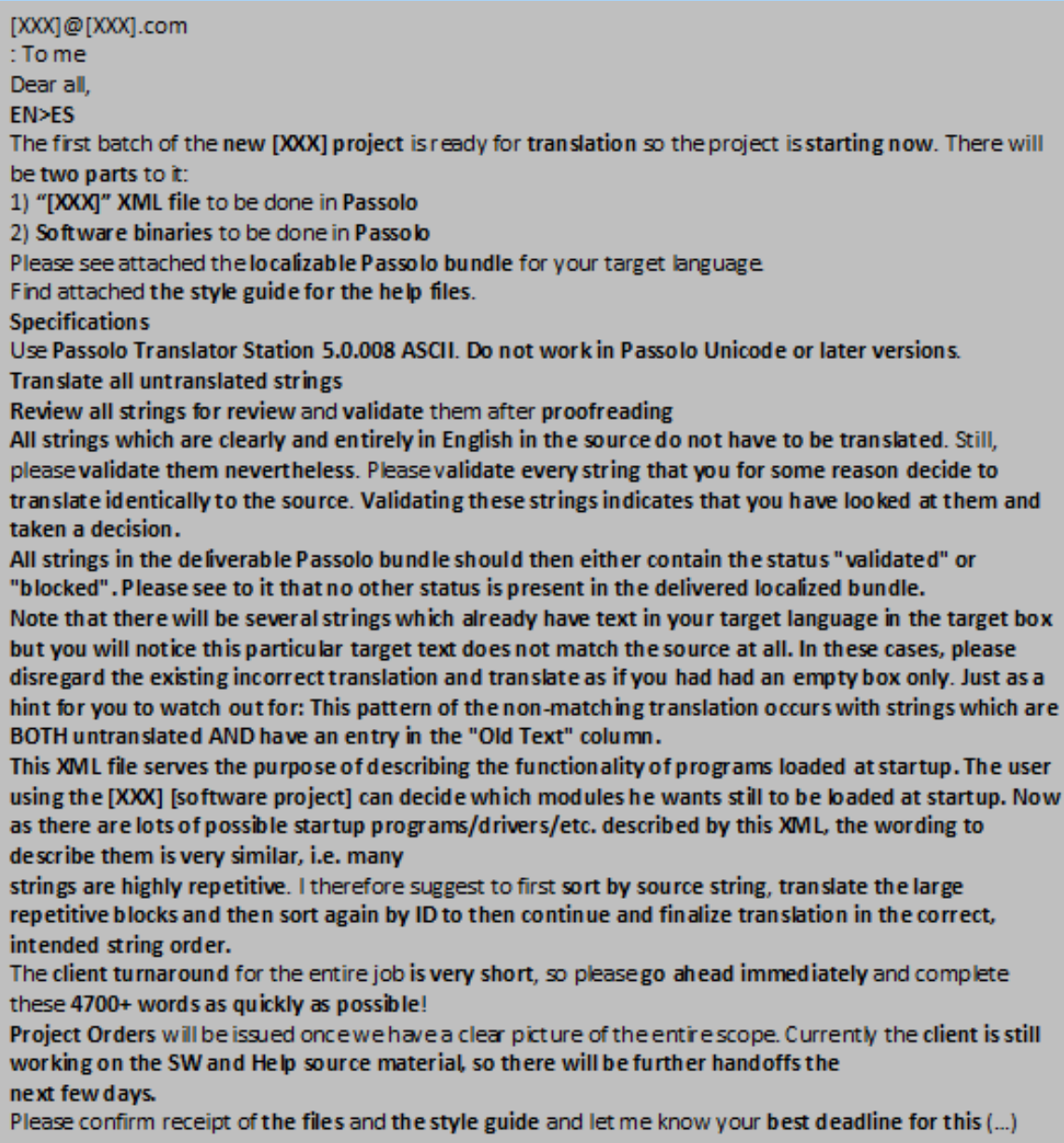

These specifications are often accompanied by supporting skopos-related documentation, as described in the example above: linguistic style guide, technical settings, source text genre ( $x \mathrm{ml}$ file and software binaries); terminology and other reference documentation, project order, etc.

When managing complex projects, there is a need for a global functionalist overview to ensure, for example, that instructions and specifications do not overlap or contradict themselves, that levels of skopoi (subordination levels) are well described and prioritised, and that requirements 
are feasible within the deadline and with regard to the level of expertise and qualifications of each professional involved (Sere, 2015; Alonso, 2016).

In this study, a number of relevant inconsistencies were detected in at least two cases. For instance, one of the projects included a plethora of different reference resources (terminology database, translation memory, parallel reference, etc.), but when the collaborating translator e-mailed her examples for the study, she mentioned how difficult this particular project was for her. When looking up specific strings or terms in the reference resources, different possible translations for a single term could be found, with no indication as to which source should be considered more reliable for each context. As Arevalillo (2015, p. 71) explains, project managers should be able to establish clear directions as to which reference resources are a priority. Alonso also reflects that some translators often find instructions so hieroglyphical that it is difficult to decipher what the client really wants (2016, p. 25).

Another translator reported an "ethical dilemma" in a project for which the client provided a very low-quality translation memory (TM) that included noticeable translation errors, and even spelling mistakes. Whenever translators are provided with a translation memory for a project, there is an assumption that the memory is to be trusted, as the memory allegedly reflects the quality that the client approves and pursues. However, if the TM quality is objectively unsatisfactory and the client has neglected to address this, translators will find it troublesome and confusing to use when making translation decisions and they will feel unsure about reporting any irregularities they find in it. The question is whether a good, aware translator is able to distinguish between non-ideal quality that clients have intentionally defined for translators to comply with, and low quality material that the clients themselves are unaware of or have neglected.

Large-volume translation and localization projects also lead to more intricate collaborative processes, which require different types of management integration and scope. Translation processes reproduce this level of complexity and generate very precise forms of interaction between team members and their roles within the project (instructions, commands, coordinating actions and compromises) (Sere, 2015). Collaborative processes also generate tacit subordination with potentially functionalist implications open to further research: for example, when a team of translators uses a shared translation memory, is their work affected by whether they are logged in under their own ID or anonymously: i.e., whether their translated segments can be traced back to them or not? Does segmentation play a subordinating role in translation decision-making? Do confidentiality issues affect the way translators approach translation processes?, etc.

An aware project manager will make an effort to identify the needs of the customer or recipient of the translation and will create guides and specifications that will help the team achieve the desired quality. Arevalillo (2015, pp. 69-71) describes how balanced specifications will determine how a project is completed, its quality control processes and final customer satisfaction after delivery. Otherwise, as Alonso (2016, p. 26) explains, insufficient specifications will be problematic. Vendors are sending more and more projects through virtual translation platforms and, as a result, translators only learn the details of the translation brief once they have accepted the job.

Highly technified and specialised project management and quality processes are consolidated when vendors seek certification and their processes are compliant with relatively recent standards (ISO, EN, etc.). In the following section the major translation industry quality standards are reviewed in the light of functionalist theories. 


\section{Functionalist foundations underlying translation quality standards?}

Quality implies a certain degree of subjectivity. As seen above, in the field of translation practice, quality is mostly related to client or target audience satisfaction. As Morón (2017) explains, one of the most widespread applications of skopos is within training and assessment contexts. More precisely, a clear skopos, because of its potential to generate a reference quality framework for everyone involved, helps to bring more transparency to any assessment process. Authors like Chesterman (2010) and Nord (2006) suggest that quality be assessed on the extent to which a translation has fulfilled its function with regard to the target context.

To contextualise and operationalise a problematic concept such as quality, it is necessary to homogenise and objectify what we understand by quality for a specific project. This is precisely why industry standards are important. Translation standards do not focus on the translation produced - this would require a universal definition of quality - but rather acknowledge that quality requirements vary from one individual project to another. The emphasis is therefore on defining translation process quality criteria. This distinction between translation as a product and translation as a process is essential in functionalist terms.

Globalisation has stimulated the creation of norms to help internationalise and standardise products and services across different national and local markets. The different standard-setting bodies (ISO, ANSI, BSI, AENOR, DIN, etc.) provide reference norms and certifications on a voluntary basis to facilitate trading and service provision (Arevalillo, 2005).

There is now a wide range of both national and international translation standards in place. According to Arevalillo (2015), the first comprehensive translation standard of a technified, contemporary nature to regulate translation services was probably EN 15038 (European Committee for Standardization, 2006), which has recently been followed by the more updated and comprehensive ISO 17100 (International Organization for Standardization, 2015). Both standards regulate quality in translation processes:

The purpose of this (EN 15038) European Standard is to establish and define the requirements for the provision of quality services by translation service providers. It encompasses the core translation process and all other related aspects involved in providing the service, including quality assurance and traceability. (European Committee for Standardization, 2006)

This (ISO 17100) International Standard specifies requirements for all aspects of the translation process directly affecting the quality and delivery of translation services. (International Organization for Standardization, 2016)

The skopos-related content of these two leading international standards has been analysed to identify items with an explicitly functionalist value.

Probably one of the most interesting aspects of these standards is the establishment of differentiated so-called "value-added services", which are defined as additional value-added services that go beyond the simple translation of texts, and may be offered by translation service providers (TSP) and which broaden the more conventional conception of translation work. The non-exhaustive list of possible value-added services included in ISO 17100 covers 23 services that are considered as different from plain translation. However, many of these services are simply an indication of a particular functionalist approach taken by translators when engaged in their professional activity. In other words, these new translation-related labels can be considered skopos-based keywords within the industry insofar as they help establish a 
predominant communicative function for a specific project type, addressing peripheral translation-related services which, in any case, require a specific understanding of the desired functionality for a specific project. Value-added services include different forms of certified or sworn translation, adaptation, localization, internationalization, transcreation, globalization, post-editing, subtitling and back-translation, which are actually translation actions defined by a specific skopos. These translation variations imply, for example, specific general directions on the expected degree of adherence to the source text or accommodation of the target context depending on the specific service. Other related services include text revision and language/culture consultancy, which undoubtedly also imply a case-based approach to client expectations vis-à-vis functionality.

However, neither of the two standards includes any express mention of skopos, brief, or the alternative term, commission. In contrast, the concept specifications features prominently and has a central place in these norms.

Although functionalist theorists have more frequently embraced the notions of brief, commission or skopos, the term specification is by no means new in TS. The concept appears in the works of Holz-Mänttäri (Produktspezifikation) (1984), Nord (1991; 2012a), Sager (1994), Risku (2009) and Vermeer (2004), always in relation to the notion of brief:

A commission comprises (or should comprise) as much detailed information as possible on the following: (1) the goal, i.e., a specification of the aim of the commission (cf. the scheme of specification factors in Nord 1988, p. 170) (Vermeer, 2004, p. 227)

Translators must interpret the specification according to the source from which it is received; in some cases, they can interact with the provider of the specification - there being also the special case of the translator interacting with the agent and the writer. (Sager, 1994, p. 142)

The mental activity of translation proceeds at the level of a declared intention, knowledge acquisition and linguistic expression. The initial stimulus and orientation which give the activity its direction is provided by the specification which, in psychological terms, states the goal of the activity. The specification permits translators to form an image of the new text, i.e., a modified form or reader expectation. (Sager, 1994, p. 214)

Annex B in ISO 17100 is titled "Agreements and Project Specifications". It includes an extensive list of 22 skopos-related elements which may constitute a complex brief or part of a translation kit. Some of these elements would be familiar for functionalist scholars (audience, purpose, specifications, etc.):

- $\quad$ Elements with both explicit and implicit skopos implications: scope and value added-services; schedule and delivery dates; quotation; use of technology (explicit and implicit skopos implications); ID recognition (explicit and implicit skopos implications), etc.

- Elements with explicit skopos implications: linguistic specifications; languages; audience, purpose; style guide, glossary, etc.

Finally, both EN 15038 and ISO 17100 include a verification phase. This final quality control takes place at the end of the translation process, just before delivery, and is directed by the project manager. The verification process consists of assessing whether the translation has actually fulfilled the specification criteria laid down by the commissioner. The foundations 
underlying this quality-control procedure seem to have much in common with functionalist theories.

\section{Conclusions}

Aspects such as focussing on the target audience and recipients, the scope of the project, and the different translation-related services provided, each with its own specific expected level of literality or creativity, all suggest the existence of some kind of overlap between the way quality control is approached in the industry and certain functionalist axioms. In this analysis of today's translation industry, the idea of skopos-based translation processes makes sense from a project quality management perspective, even though explicit specifications and briefs are not always clearly provided. While ruling principles seem closely related, terminology has evolved differently, insofar that translation market standards have preferred to use the term specifications rather than more scholarly, abstract alternatives like skopos, or terms that have become a little outdated for some types of projects (the term brief, for example, no longer reflects the managerial complexity and engineering of localization kits).

By qualitatively analysing additional materials from real projects, three possible brief types were identified, usually highly depending on the type of project, ranging from a virtual absence of directions to multi-layered brief systems. Designing consistent and efficient multi-layered brief systems requires a global, function-oriented vision of the project. Otherwise, specifications will hinder the translation process and have a negative impact on quality compliance.

These reflections pave the way for future research focused on subordinating factors in translation and localization processes, both explicit and implicit; sociological research into skopos issues depending on the type of project research involved, sociological perceptions of the different brief types from the perspective of translators themselves; text genres born out of managerial and quality assurance systems, and so on. The ideas addressed could also be applicable to translation training, as they help integrate theory and practice in situated training contexts (theoretical scaffolding), as explained in Calvo (2015).

Acknowledgements: The author thanks Emeritus Professor Christiane Nord for her stimulating comments, criticism, and suggestions on this study.

\section{References}

Alonso, E. \& Calvo, E. (2015). Developing a blueprint for a technology-mediated approach to Translation Studies. Meta, 60(1). Retrieved from: https://www.erudit.org/fr/revues/meta/2015-v60-n1-meta02005/1032403ar .pdf

Alonso, E. (2016). Conflict, opacity and mistrust in the digital management of professional translation projects. Translation \& Interpreting, 8(1), 19-29. Retrieved from: http://www.trans-int.org/index.php/transint/article/view/497

Arevalillo, J. (2005). La norma europea de calidad EN-15038 para servicios de traducción". ASATI. Retrieved from http://www.asati.es/img/art/EN15038. pdf

Arevalillo, J. (2015). Gestión de proyectos, control de calidad y categorización de errores a partir del proceso de revisión. Thesis. Málaga: UMA. Retrieved 
from https://riuma.uma.es/xmlui/bitstream/handle/10630/11253/TD_ Arevalillo_Doval.pdf?sequence $=1$

Byrne, J. (2006). Technical translation: Usability strategies for translating technical documentation. Dordrecht: Springer.

Byrne, J. (2012). Scientific and technical translation explained. Manchester: St. Jerome Publishing.

Calvo, E. (2015). Scaffolding translation skills through situated training approaches. The Interpreter and Translator Trainer. 9(3). Retrieved from: http://www.tandfonline.com/doi/abs/10.1080/1750399X.2015.1103107

Chesterman, A. (2010). Skopos Theory: A retrospective assessment. In W. Kallmeyer et al. (Eds.), Perspektiven auf Kommunikation. (pp. 209-225). Berlin: SAXA.

Chesterman, A. \& Wagner, E. (2002). Can theory help translators? Manchester: St. Jerome.

De la Cova, E. (2012). XLIFF: ventajas y desventajas para la traducción. In E. Ortega (Dir.), Traducir la cultura (pp. 941-952). Granada: Comares.

De la Cova, E. (2016). Translation challenges in the localization of web applications. Sendebar. 27(1). Retrieved from http://revistaseug.ugr.es/public/sendebar/ sendebar27 completo.pdf\#page $=235$

Dunne, K., \& Dunne, E. (2011). Translation and localization project management. London: John Benjamins.

European Committee for Standardization (2006). UNE-EN-15038: Servicios de traducción. Brussels: CEN.

Esselink, B. (2002). Localization engineering: the dream job? Traducció $i$ Tecnologies de la Informació i la Comunicació (1). Retrieved from http:/www.fti.uab.es/ tradumatica/revista/articles/besselink/besselink.PDF

Fraser, J. (1996). The translator investigated. The Translator, 2(1), 65-79. Retrieved from http://www.tandfonline.com/doi/abs/10.1080/13556509.1996.10798964

Holz-Mänttäri, J. (1984). Translatorisches Handeln. Helsinki: Suomalainen Tiedeakademia.

International Organization for Standardization (2015). ISO-17100. Translation services. Geneve: ISO

Jensen, M.N. (2009). Professional translators' establishment of skopos: a brief study. Thesis. Aahrus: ISE. Retrieved from http://pure.au.dk/portal/files/7795/ Professional_Translators_Establishment_of_Skopos.pdf

Martín de León, C. (2008). Skopos and beyond. Target, 20(1), 1-28.

Morón, M. (2017). El catálogo técnico y sus zonas de intervención. Hermeneus, 19.

Nord, Ch. (1988). Textanalyse und Übersetzen. Heidelberg: Groos.

Nord, Ch. (1991). Text analysis in translation. Amsterdam: Rodopi.

Nord, Ch. (1997). Translating as a purposeful activity. Manchester: St. Jerome.

Nord, Ch. (2012a). Quo vadis, functional translatology? Target, 1(24) 26-43. Retrieved from https://benjamins.com/online/target/articles/target.24.1.03nor

Nord, Ch. (2012b). Texto base-texto meta. Un modelo funcional de análisis pretraslativo. Castelló: Servei de Publicacions.

Nord. Ch. (2006). Loyalty and fidelity in specialized translation. Confluências, 4(1), 29-41. Retrieved from http://web.letras.up.pt/egalvao/TTCIP_Nord\%20 loyatly\%20and\%20fidelity.pdf

Parra, S (2005). La revisión de traducciones en la traductología. Thesis. Granada: UGR. Retrieved from http://hera.ugr.es/tesisugr/15472905.pdf

Pym, A. (2011). What technology does to translating. Translation \& Interpreting, $3(1), \quad 1-9$. Retrieved from http://transint.org/index.php/transint/article/ viewFile/121/81

Reiß, K., \& Vermeer, H. J. ([1984] 2013). Towards a general theory of translational action. Manchester: St. Jerome.

Risku, H. (2009). Translationsmanagement: interkulturelle Fachkommunikation im Informationszeitalter. Tübingen: Narr.

Roturier, J. (2015). Localizing apps. Oxon: Routledge

Sager, J. (1994). Language engineering and translation. Philadelphia: John Benjamins.

Schjoldager, A. \& Zethsen, K. (2003). How skopos is established by the professional translator. In A. Veisbergs (Ed.), 3rd Riga Symposium on Pragmatic Aspects of Translation (pp. 140-152). Riga.

Translation \& Interpreting Vol 10 No 1 (2018) 
Sere, K. (2015). Risk management in translation projects. Thesis. Haute École de Bruxelles, Brussels. Retrieved from http://www.translation-projectmanagement.com/download/KSERE RMinTP.pdf

Sunwoo, M. (2007). Operationalizing the translation purpose (skopos). MuTra conference proceedings. Retrieved from http://www.euroconferences.info/ proceedings/2007_Proceedings/2007_Sunwoo_Min.pdf

Vermeer, H. J. (1978). Ein Rahmen für eine allgemeine Translationstheorie. Lebende Sprachen, 23(1), 99-102.

Vermeer, H. J. (1996). A skopos theory of translation. Heidelberg: Textcontext.

Vermeer, H. J. (2004). Skopos and commission in translational action. In L. Venuti (Ed.), The Translation Studies reader (pp. 227-238). Oxon: Routledge. 